\title{
Design and Implementation of Network Management System of Laboratory Chunxi Zhao
}

Jilin Agricultural University, Changchun 130118, China

aemail: 10821395@qq.com

Keywords: Network; Management; the system framework

\begin{abstract}
There are many disadvantages in the traditional teaching management mode, which can not meet the needs of the rapid development of today's information technology. Relying on the campus network as the background, the use of advanced information management platform, the development of a set of open laboratory network management system, the system framework, architecture, functional modules were designed and studied.
\end{abstract}

\section{Introduction}

The continuous development of higher education in our country has been popularized, which reflects the education of our country, and requires all of the people to master the scientific knowledge. The spread of education, but the employer to talented person's request is more and more high, is no longer a need theory type talents, employing units to analyze and solve practical problems in will continue to ask for a raise of university personnel training is a big challenge and the training of talents in Colleges and universities must to change their ideas [1]. Universities have begun to student's culture by the transformation of the original theory talent slowly into theory and practice of comprehensive talent, strengthen students during the learning process practical ability training, Ministry of education of College Experimental Teaching and laboratory construction presents higher, more specific requirements. In the face of social standards, in the new era of Education under the influence, training innovation, theory and practice of combining the comprehensive talents, improve the quality of the quality education, we must carry on the reform to the original experimental teaching and laboratory management system, and strive to explore suitable for the development of colleges and universities in the experimental room management system, and the establishment of the new era to adapt to the development of laboratory management system. In this regard the construction of some colleges and universities in our country to walk in front of the comparison has been carried out construction or practice, open laboratory network management model is the construction of the new era has a more significant impact [2]. While the traditional management mode is very difficult to realize the construction and management of open laboratory, it is necessary to have a set of professional system to manage the. With the popularity of the network, campus network construction also in the continuous development and improvement, on the basis of the campus network background, to adapt to the needs of the development of the school, design and development of a set to suit the demand of current teaching open laboratory network management system is required [3].

LIMS (laboratory information management system of laboratory information management system) is through the computer network technology on the remote data storage and access, fast data processing technology to the laboratory for comprehensive management of the computer software and hardware system, able to complete laboratory data and information collection, analysis, reporting and management. Open laboratory information management system development and application of laboratory conducive to the realization of automatic operation, information management and paperless office objective, so as to improve the efficiency of laboratory management work had on, reduce operating costs play a crucial role [4]. 
In the traditional teaching mode, is often the teacher centered, teacher teaching in the classroom, the students were

Dynamic acceptance, the knowledge of the classroom cannot digest and absorb. To enable teachers to prepare lessons focus on the acquisition of knowledge, teachers at this time as the film's director, and the students act as the completion of tasks as indicated by the director actor is completely a Yinzi printed, does not have its own unique originality, fully playing by the rules.

This is detrimental to the development of society, and cannot adapt to the needs of the new century. The use of the study of domestic and foreign related field, on the status of the currently used in the laboratory, equipment management, experiment booking, equipment maintenance application, equipment scrapped for, the use of advanced computer network technology, design a set of "open laboratory tube system". Through the advanced computer technology, which they link between messy equipment of the school management, the use of confusion, maintenance difficult to apply and pre experiental difficulties laboratory comprehensive management, a set of laboratory network management application system development..

\section{System development goal}

Help to improve the teaching thought

Combined with the characteristics of experimental teaching of the college, the introduction of foreign advanced teaching ideas, using the system management mode, change the traditional teaching mode, can promote students' learning initiative, from the original passive into active.

Help to improve the teaching thought.

Is conducive to the promotion of the management of the laboratory management laboratory relative to other work is more complicated, such as equipment information management, borrow management, student experiment report management, in our hospital using artificial management, old ways, and easy to lose. Using the experimental management system, using the network for storage, network management, can improve the efficiency of the management of experimental management, cost savings.

Is conducive to improve the enthusiasm of students

The traditional mode of teaching is the students listen, teacher, teacher speak much, students listen to how many, the cramming method of teaching, students lack enthusiasm for learning, the students lack of awareness of innovation. Open laboratory network management system is put into use, it is conducive to the exchange of students and teachers, students' questions he got timely answers, greatly improving the enthusiasm of students learning.

\section{The design target of the system}

The design principle of the system global considerations, through various departments, equipment management and laboratory management, teacher / student laboratory appointment, scrap and maintenance management module is laboratory management of the daily business, combined with requirements analysis and studies the actual needs of the various departments to design and between them are interrelated and organic combination. Through the adjustment of information among these modules, mutual information association, realize the information between them access to each other, streamline business processes of the laboratory management, laboratory management work orderly, the work of the laboratory scientific management, standardize the work flow. The design target of the system, relying on the campus network environment, make full use of existing hardware resources, the use of advanced computer network technology and database technology development, the three layer model of B / S framework, web mode based on self-designed development of open laboratory network management system, as shown in Figure 1. Optimization of the management of laboratory, the complicated procedures simplified, the work to achieve network management. Open by appointment it is convenient for teachers and students using laboratory experiments were conducted, to help teachers scientific research work, the students innovative practice get sufficient practice, promote the students' learning enthusiasm. 


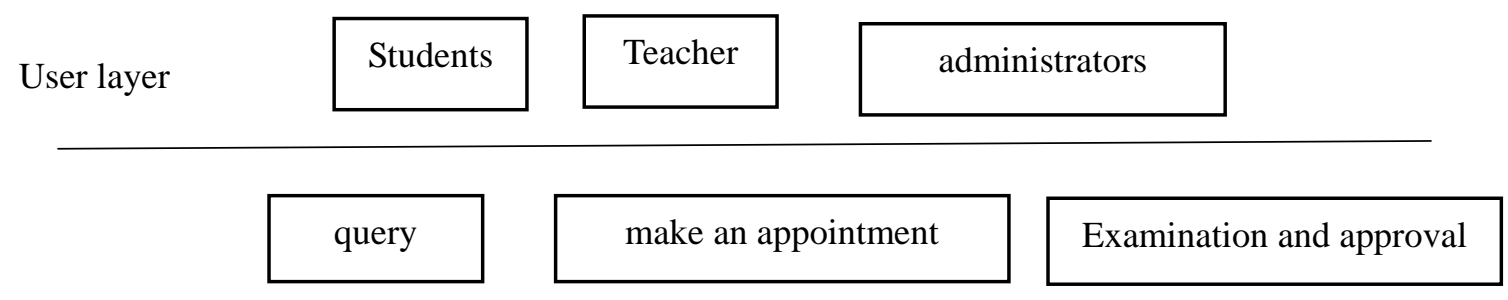

Logic layer

Experiment report 1

Figure1. Structure diagram of experimental system
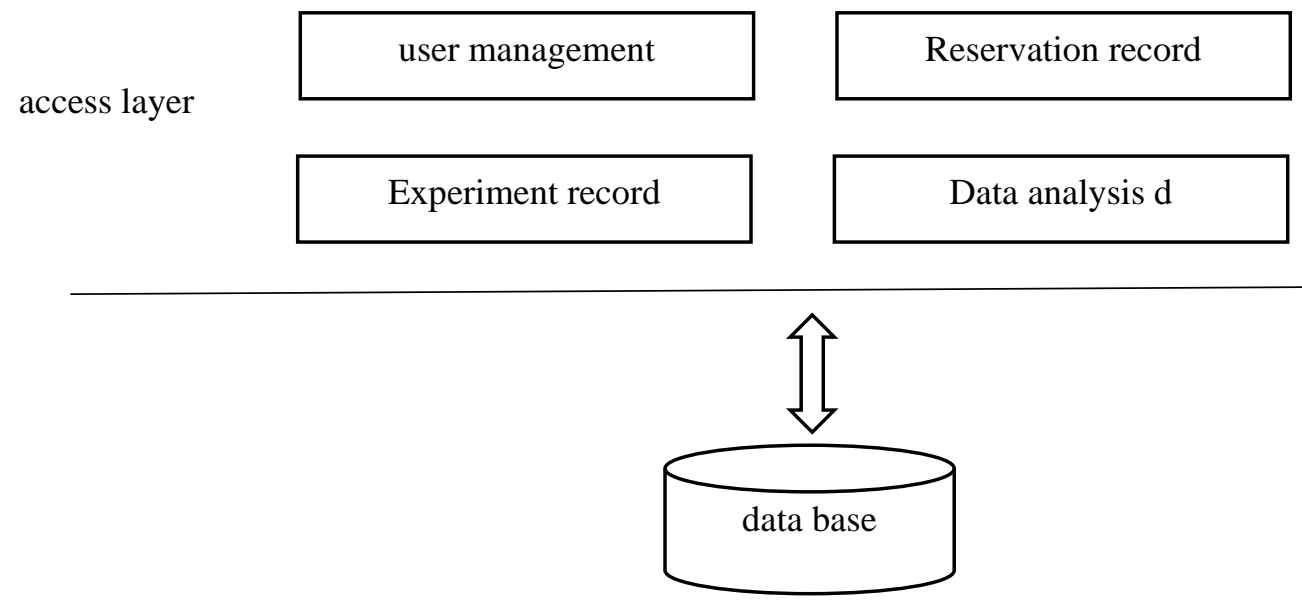

Figure2. Structure of teaching resources library

\section{System architecture design}

The three layer architecture is to add a "middle layer" between the client and the database, also called the component layer. Here said the three layer system, not referring to the three levels of physical, not simply placed three machines is three layer system structure, is not only a B / s application is the three layers system structure, three layer is refers to the logical three layer, even if these three layers are placed into a machine. In general, the three tier architecture is to divide the application into:

Presentation layer (U\}, business logic layer (BLL), data access layer (DAL). The purpose of distinguishing the level is to "high cohesion, low coupling" design ideas.

The presentation layer is the user application layer (UI: is mainly to play the input and output of information, the user to watch more intuitive. In order to consider the security of the system, it is necessary to verify the legitimate users when users access or view.

Business logic layer (BLL): mainly responsible for operation of the data layer, middle layer in the three layer plays a connecting link between the preceding and the following, such as database connection, in representation layer according to the user's request to generate retrieval statement or update the database, and return the result to the user terminal.

3 , the data access layer (DAL: mainly responsible for database access, such as data storage and retrieval, the layer of the affairs of the direct operation of the database, according to data increase, delete, modify, query and other are in access layer occurs. 
System architecture is the need for the needs of the technology planning, system functions, design and implementation. The framework includes the components of system decomposition, the practical function of the system, the correlation, the interaction, the compatibility and the friendly interface and so on. System architecture is the organization or structure of the important component of the system, which is composed of the interface and the components that are being reduced. What kind of system architecture is selected, which will be the direction of the development of the relationship system.

Throughout the history of the computer program development process, analyzed and summarized the commonly used network architecture has two kinds, the first is: the client / server architecture (client / server), referred to as the C / S structure; the other is based on the browser and server architecture (Brower/ server (B / S structure.

The development of open laboratory network management system is based on B / S structure mode, the database server hosted by the network management center, through the server for public laboratory data centralized management, storage, maintenance, ensure the data real-time, consistency and safety, the departments of the scattered data has been effectively controlled. Through the Internet and enterprise networks to connect the database to achieve information sharing, for between departments mutually consult, resource sharing, effectively solve the college at present equipment problems; laboratory opening mode, teachers and students can through the Internet or campus network login to the laboratory network management system query related information, booking laboratory. Out of school teachers or students can also log on to the open laboratory network management system Internet to check the relevant laboratory.

System function module

According to actual situation of the demand analysis and the school of management, in the campus network based on, I open laboratory network management system using B / S Architecture Web mode, this system the main function modules include: management of laboratory equipment, laboratory management, file management, system management and data query and statistical analysis module management, they can independently of each other, and can be related to each other, to form a whole.

\section{System management function}

This module mainly consists of user management, rights management, and data management and information security management module. Users according to the actual use of the situation is divided into categories: College Management (leadership, decision makers), equipment managers, laboratory managers, teachers, students and the system administrator. Each of them travel their duties, do not interfere with each other, there are different permissions to manage and use the system, the specific design is as follows:

System administrator rights. System administrator is the data maintenance and management of the whole system:

User management, increase the new user, the user has to edit, modify, delete, etc.

Database management, database backup and recovery.

System maintenance and security monitoring, check the website's visit, system log management.

System information management, information management, editing, modify, delete, etc.

Function of the device administrator permissions, is mainly responsible for the laboratory equipment management, including the maintenance and repair of the equipment information permissions. Equipment information input, edit, delete, query and other functions.

Equipment lending, responsible for equipment lending, the implementation of the use of the responsible person. Equipment scrap, processing equipment scrap application. Equipment maintenance, equipment maintenance cost management. Generate statistical analysis report, generate analysis report for equipment usage. Print report form. Teacher function authority

Laboratory inquiry appointment, mainly to see the use of laboratory, in order to carry out an open appointment. Student information query, check the experimental project to make an appointment with the student's information. Experiment report management and correction, on the 
students to submit an experimental report with access, delete, correction.

Experiment well inquiry, inquiry experiment can normally use the device. Student function authority Experiment item inquiry and booking, mainly to check the number of the experimental project to make an appointment, so that the experimental project

Open an appointment.

Experiment results query, to see their participation in the results of the experimental project.

Type of equipment and integrity check, check the type and condition of the equipment.

Laboratory open appointment function design, according to the needs analysis, including laboratory resources inquiries, open appointment,

The functional design of experiment equipment, laboratory schedule query.

Lab resource query, mainly laboratory equipment.

Open appointment, open experiment project, student appointment experiment project.

Good laboratory equipment inquiries, real-time control of laboratory equipment is normal.

The laboratory curriculum inquiry, inquiry Laboratory Textbook table.

Equipment management is mainly to the equipment management, including equipment procurement plan, equipment running status, equipment

Maintenance / scrap, low value consumables management. Specific design is as follows:

Equipment procurement plan, the use of the Department to report to the superior equipment procurement plan.

Equipment information input and edit, add new equipment information to the database, and edit the equipment information,

Modify, delete.

Equipment usage statistics and analysis, classification and statistics of the existing equipment.

Equipment maintenance management, the use of the Department to the equipment management department, 1 submitted to the maintenance failure.

Equipment scrap management, the use of the equipment management department to put forward equipment scrapped. Low value consumables management, the use of the Department to the equipment management department with low value and easy to use products.

Document management is the management of documents. Including: experimental reports, announcements. Student experiment report, student electronic file experiment report storage management.

Laboratory bulletin management, storage management of laboratory use notification files.

\section{Conclusion}

A new generation of for open experimental teaching of comprehensive resource network support platform to the informationization, intelligent, rich in resources, features a variety of characteristics completely replaced the early artificial management mode and past single function experiment booking management system, embodies the with students as the center of teaching thought, accelerate the pace of information construction of the school, to optimize the allocation of resources of experimental teaching, improve the quality of experimental teaching. Looking to the future, the intercollegiate cooperation and integration of remote collaborative open network experimental platform through hardware, software, and personnel resources share to personnel training of high level and high efficiency and social productivity of the sustained and rapid growth.

\section{References}

[1] Fan K Y, Guo H J. Research of Distributed Model of Network Management System [J]. Applied Mechanics \& Materials, 2014, 539(2):286-290.

[2] Henderson G S, Perry W B, Franklin T D, et al. Network management system: US, US 6058103 $\mathrm{A}[\mathrm{P}] .2000$. 
[3] Pisello T, Crossmier D, Ashton P. Network management system having virtual catalog overview of files distributive stored across network domain: EP, US 5495607 A[P]. 1996.

[4] Liao H, Xu Z. Network Management System is delivered as turnkey service. [J]. International Journal of Intelligent Systems, 2014, 29(11):971-993. 